\title{
Managerial Recognition as an Incentive for Innovation Platform Engagement: A Field Experiment and Interview Study at NASA
}

\section{Citation}

Gallus, Jana, Olivia S. Jung, and Karim R. Lakhani. "Managerial Recognition as an Incentive for Innovation Platform Engagement: A Field Experiment and Interview Study at NASA." Harvard Business School Working Paper, No. 20-059, November 2019.

\section{Permanent link}

http://nrs.harvard.edu/urn-3:HUL.InstRepos:41945645

\section{Terms of Use}

This article was downloaded from Harvard University's DASH repository, and is made available under the terms and conditions applicable to Other Posted Material, as set forth at http:// nrs.harvard.edu/urn-3:HUL.InstRepos:dash.current.terms-of-use\#LAA

\section{Share Your Story}

The Harvard community has made this article openly available. Please share how this access benefits you. Submit a story. 


\section{Managerial Recognition as an Incentive for Innovation Platform} Engagement: A Field Experiment and Interview Study at NASA

Jana Gallus

Olivia S. Jung

Karim R. Lakhani

Working Paper 20-059 


\section{Managerial Recognition as an Incentive for Innovation Platform Engagement: A Field Experiment and Interview Study at NASA}

Jana Gallus

University of California, Los Angeles

Olivia S. Jung

Harvard Business School

Karim R. Lakhani

Harvard Business School

Working Paper 20-059

Copyright (C) 2019 by Jana Gallus, Olivia S. Jung, and Karim R. Lakhani.

Working papers are in draft form. This working paper is distributed for purposes of comment and discussion only. It may not be reproduced without permission of the copyright holder. Copies of working papers are available from the author.

Funding for this research was provided in part by Harvard Business School and NASA Open Innovation Research, award \#NNX16AC77A. 


\title{
Managerial recognition as an incentive for innovation platform engagement: A field experiment and interview study at NASA
}

\author{
Jana Gallus ${ }^{1}$, Olivia S. Jung², Karim R. Lakhani²,3,4 \\ ${ }^{1}$ UCLA Anderson School of Management, ${ }^{2}$ Harvard Business School, ${ }^{3}$ Laboratory for Innovation \\ Science, ${ }^{4}$ National Bureau of Economic Research
}

\begin{abstract}
Incentivizing employees to engage with novel innovation mechanisms and contribute to collective problem-solving can be difficult. We run a field experiment with NASA $(\mathrm{N}=11,192)$ to study two widely used classes of non-financial incentives: recognition (of managers, peers, online platform participants), and the prospect of advancing the organizational mission. Our analysis shows that managerial recognition has a significant positive effect on employees' engagement with the problem-solving platform. The other incentives are not found to be effective. A follow-up interview study suggests that (1) managerial recognition works through signaling the platform's legitimacy in a context of uncertainty, as well as through offering managerial attention and appreciation; (2) recognition interacts with employees’ job proximity to the organization's mission and can be particularly motivating for employees with distant job functions; (3) organizations where the appeal of the organizational mission is already strong may face difficulties in using the mission as an instrumental incentive.
\end{abstract}




\section{INTRODUCTION}

Many organizations are adopting peer-to-peer platforms to promote innovation and collective problem-solving. Yet, motivating employees to engage with such newly introduced innovation mechanisms is difficult (e.g., Lifshitz-Assaf, 2018). Monetary incentives are not the sole, and often not even the primary motivation behind people’s creative and innovative work (e.g., Amabile 1998; von Hippel, 2017). What alternative incentives do organizations have at their disposal for motivating engagement with novel innovation practices? Organizational award programs are among the most widely used forms of nonfinancial incentives (Frey, 2007; Gubler, Larkin, \& Pierce, 2016), and yet the empirical literature on their effects is still in its beginnings (Frey \& Gallus, 2017a). A second prevalent class of nonfinancial incentives seeks to motivate workers through highlighting how their work contributes to the mission of the organization (Cassar \& Meier, 2018).

We run a field experiment (Study 1) with the U.S. National Aeronautics and Space Administration (NASA) to study these two widely-used classes of non-financial incentives: recognition and mission. There is a wide variety of recognition awards, ranging from titles (such as the IBM Fellows), to trophies, plaques, and online recognition boards. One important dimension that distinguishes different types of organizational awards is the audience involved. We exogenously vary the expected audience of recognition in the same organizational context in the field: managers, immediate peers, or online platform participants. We compare the effectiveness of these recognition awards to the effectiveness of using mission as an explicit incentive to motivate platform engagement. Running a field experiment with NASA allows us to cleanly identify causal effects of those different incentives. The incentives are announced in emails sent to 11,192 employees, and platform engagement is measured as the share of employees returning to the platform in the week following treatment administration.

Our analysis shows that the prospect of managerial recognition has a significant positive effect on subsequent platform engagement. We do not find support for the effectiveness of the other incentives. An interview study (Study 2) with 53 NASA employees sheds light on the mechanisms. It highlights the importance of signaling about the platform’s legitimacy. In a context of uncertainty around the new 
innovation platform, managerial recognition signaled that platform engagement was legitimate and important. In contrast, recognition in front of immediate peers and among online platform participants was ineffective or even demotivating since the signal-worthiness of the underlying task was questionable. A second mechanism behind the effects of managerial recognition was managerial attention and appreciation, which seemed to have been particularly motivating for employees whose jobs were relatively removed from the organizational mission. The prospect of recognition provided them with an opportunity to be seen as supporting the organization's new innovation initiative. Lastly, employing the organization's mission to motivate task engagement was met with skepticism because employees were already highly mission motivated, such that highlighting mission did not further increase motivation on the intensive margin.

Our multi-method research design combines the experimental approach with qualitative data (Fine \& Elsbach, 2000) to analyze the micro-foundations of organizations (Bitektine \& Haack, 2015; Fine \& Hallett, 2014; Schilke, 2018). The multi-method design allows us to develop richer explanations of relationships among novel and existing constructs. This is particularly useful for research on emerging topics, such as incentivizing engagement with new innovation mechanisms within organizations (Edmondson \& McManus, 2007). Our findings contribute to the literatures on non-financial incentivesnotably recognition and mission motivation—, innovation platform engagement, and change management.

The remainder of this paper is structured as follows: As a backdrop for the current research, we provide a review of relevant studies on non-financial incentives relating to open innovation. We then describe the empirical context of our study, including the innovation platform implemented at NASA. Next, we describe our field experimental design and then present and briefly discuss the results. This is followed by the interview study setup, analysis, and results. We conclude with theoretical and practical implications of our findings, and avenues for future research. 


\section{Non-financial Incentives and Innovation Platform Engagement}

Organizations are increasingly adopting IT-based platforms that facilitate the exchange of ideas and expertise among employees within the organization (Erickson, Trauth, \& Petrick, 2012; Malhotra, Majchrzak, Kesebi, \& Looram, 2017). However, despite the promise of such platforms, overcoming skepticism and motivating platform engagement can be difficult if there are no network effects to begin with and if the platform's horizontal nature is at odds with a predominantly hierarchical organizational structure. Paying employees to support the organizational change and adoption of the platform is of limited use. It may even backfire. There is by now ample research showing the ineffectiveness and potentially deleterious effects of using money in domains ranging from citizenship behaviors (Frey 1997; Gneezy, Meier, Rey-Biel 2011) to creativity and innovation (Amabile 1998). The use of incentives is particularly difficult where individuals have pro-social and intrinsic motivations that risk being undermined. This begs the question of which alternatives organizations have for increasing or sustaining people’s motivations.

Recognition is a particularly promising incentive because it has the potential to bolster people’s intrinsic and pro-social motivations by providing appreciation in public (Gallus \& Frey, 2016). We contribute to the emerging literature on awards and recognition incentives (Bradler, Dur, Neckermann, \& Non, 2016; Gallus, 2017; Gubler, Larkin, \& Pierce, 2016; Kosfeld \& Neckermann, 2011; Rossman \& Schilke, 2014). Studying the causal effects of different types of recognition incentives within the same field context is challenging. We do so by studying the ex ante effects of promised recognition and experimentally vary the expected audience. We focus on recognition in the context of newly adopted, peer-based innovation mechanisms, which are marked by uncertainty around the signal-worthiness of the underlying task.

Recent research suggests that recognition can be highly effective in motivating peer-based and new innovation initiatives. These studies have looked at different audiences in isolation. In a field experiment run within the Wikipedia community, Gallus (2017) finds that a purely symbolic award scheme backed by senior contributors causally increases the retention rate among new contributors by 
$20 \%$ in the month after the award was posted on contributors' personal profile pages. The treatment effect was long-lasting; it continued to be significant for an entire year after the intervention. Being appreciated by senior peers and not feeling “lost in the crowd” (Latané, Williams, \& Harkins, 1979) was an important mechanism driving these results. This is in line with theoretical research suggesting the importance of managerial attention (Dur, 2009; and Halac \& Prat, 2016), as well as with experiments (albeit not in the context of innovation) that found positive effects of recognition given by the managing director (Kosfeld \& Neckermann, 2011) or the head of the research institute (Bradler et al., 2016). Similarly, appreciation and attention by the community of users more generally (Huberman, Romero, \& Wu, 2009; Zhang \& Zhu, 2011), by lower- or equal-status peers (Restivo \& van de Rijt, 2012, 2014), or by the platformhosting firm (Dahlander \& Piezunka, 2014; Jeppesen \& Frederiksen, 2006; Piezunka \& Dahlander, 2018) have been found to be important sources of motivation.

It is still an open question which form of audience is the most effective, and under what conditions. For instance, peer recognition may be generally motivating in a largely open and peer-based innovation community, but it may also be limited in a context of uncertainty around the signal-worthiness of platform engagement. Managerial recognition, on the other hand, may be at odds with the peer-based nature of many platforms, but it could be an important source for signaling and legitimacy.

A second class of non-financial incentives seeks to motivate workers through the meaning of work (Carton, 2018; Cassar \& Meier, 2018). The mission of an organization can give an important sense of meaning and purpose and can thus increase motivation and performance (Cassar \& Meier, 2018). Unlike lower-order organizational goals that tend to be specific, discrete, and measurable, an organization’s mission represents abstract aims (e.g., “advance science”) and abiding ambitions (Bateman, O’Neill, \& Kenworthy-U’Ren, 2002). It is often argued that employees find these broad, timeless aspirations compelling as they epitomize the organization's shared purpose and values (Shamir, House, \& Arthur, 1993). Recent research suggests that how the organization's mission is conveyed and perceived may determine the effectiveness of using mission as an incentive. In an inductive analysis of President John F. Kennedy and other leaders of NASA communicating NASA's ultimate aspirations to 
employees in the 1960's, Carton (2018) finds that leaders' sensegiving actions allowed employees to make connections between NASA's mission and everyday work. Leaders' written and verbal messages outlining the relationship between day-to-day work and organizational aims positioned employees to view their work ("mopping the floors") as enacting the higher organizational mission ("putting a man on the moon”).

Relatedly, there is a burgeoning literature showing, for instance, that a firm’s pro-social initiatives and social mission can lower wage demands (Burbano, 2016) and increase the size and quality of the applicant pool (Hedblom, Hickman, \& List, 2016). One interesting and relevant question is whether and how instrumentally highlighting the organization's mission can motivate workers who have self-selected into an organization based in large part on their affinity to the organizational mission, such as is the case for NASA (Carton, 2018).

Another option for motivating workers to engage in a new innovation platform is to provide information about the platform's effectiveness. We will include it as an additional experimental arm, knowing that it alone is often of limited use in motivating behavior change (Thaler \& Sunstein, 2008).

\section{STUDY SETTING: NASA AND NASA@WORK}

Studying non-financial incentives within the U.S. National Aeronautics and Space Administration (NASA) has several major advantages. First, NASA established an organization-wide online innovation platform, called NASA@WORK, in 2012. Its implementation aimed to inspire innovation through knowledge sharing, facilitate crowdsourcing, and break down silos across the agency. In contrast to outward-facing and competitive open innovation platforms (e.g., Boudreau, Lacetera, \& Lakhani, 2011; Jeppesen \& Lakhani, 2010), NASA@WORK is an inner-organizational platform set up for employees to draw from each other's expertise and ideas. While several studies analyze incentives on competitive open innovation platforms, we still have a limited understanding of incentives in collaborative, innerorganizational contexts. Second, given the important role played by NASA, the agency has been the subject of a rich body of research, which has examined factors affecting innovation including the 
agency’s culture (Vaughn, 1996, 2006), knowledge management processes (Lifshitz-Assaf, 2018;

Majchrzak, Cooper, \& Neece, 2004), and the meaning of work (Carton, 2018). The insights from this literature allow us to delve into whether and how anticipated recognition and organizational mission motivate collaborative innovation. Third, we deliberately chose an organization where the appeal of the mission is an important component in the self-selection of individuals into the organization. This makes it particularly interesting to study non-financial incentives, and the role of mission in particular, at NASA.

Any NASA employees (civil servants, contractors) can contribute to NASA@WORK. To engage with the platform, employees create a user profile using their real name and center affiliation. All posts are publicly visible and tied to that username. The platform is akin to an online forum, in which users can post questions or problems (i.e., become a “challenge owner”), post answers or solutions (i.e., become a “challenge solver”), respond to other people’s submissions, or browse and learn about initiatives and projects across the agency. The latter was an important goal behind setting up the platform, which was intended to break down inner-organizational silos. The challenge owner determines the length of the submission period and selects up to two winners from the pool of contributors. Winners initially received monetary prizes, but these had to be discontinued due to the government sequestration. This made the search for non-financial incentives a priority and motivated the research collaboration. We worked closely together with the Center of Excellence for Collaborative Innovation (CoECI) at the NASA Johnson Space Center, which manages the platform.

NASA's primary interest was increasing the share of employees who would return to the platform as a result of the treatments. Any subsequent postings would depend on the content populating the platform, which was sparse. The platform engagement variable was considered the most important first step at this early stage of the platform, where there were no network effects to benefit from. The variable is moreover meaningful because logging back in is costly in terms of time, as there are multiple alternative uses of what is mostly employees’ spare time. Online platform firms such as Facebook invest heavily in making logging in as easy as possible because of its importance for subsequent content provision and consumption, but security protocols within organizations prevent such seamless 
integrations. Thus, logging in requires effort on the part of employees and is prerequisite for addressing the chicken-and-egg problem of content contribution and consumption afflicting platforms at their inception (Kane \& Ransbotham, 2016). Lastly, in online communities, members differ in their interaction patterns, with some interacting frequently and others reading messages but rarely posting content on their own (e.g., Hammond, 2000). For inner-organizational platforms, employees’ perusing the content can be highly valuable. It furthers employees’ acquisition of firm-specific knowledge and learning about innovation efforts across the organization, with the potential that they encounter problems they may have solutions for.

The challenges on the platform can range from broad questions seeking to initiate a collective brainstorm to highly technical and well-defined problems. For example, one challenge owner asked for ideas as her work group sought to expand targets monitored (e.g., analytes, biomarkers, compounds) on the International Space Station during long-duration missions. In a more specific challenge, another challenge owner asked for vendors and technology applications to develop a helmet that could quickly and seamlessly change its tint to protect the astronaut's eyes from solar radiation without having to carry a second visor material. Not all challenges asked for technical or scientific input. For instance, one challenge asked for design ideas for a crosswalk in front of the Johnson Space Center.

In Table 1, we describe the population of NASA@WORK users; i.e., NASA employees who had a registered account on the platform at the time of the experiment. The population is evenly split among civil servants (51.2\%) and contractors (48.8\%). The centers with the strongest representation are Johnson Space Center (28.2\%), Kennedy Space Center (15.9\%), and Marshall Space Flight Center (12\%). From its inception to the time of our experiment, 101 users ( $0.6 \%$ of the platform population) had posted and managed a challenge on the platform (only 11 users had owned more than one challenge). More than half of the challenge owners were affiliated with JSC, although users from JSC constituted only $28 \%$ of the platform population. 174 users (1.04\%) had ever won a challenge (only 27 users had won more than one challenge, and 12 users had both owned and solved a challenge). While the group of challenge solvers 
differs somewhat less from the overall population of registered users than does the group of challenge owners, civil servants were disproportionately represented among challenge solvers (63\%).

As few employees make any postings and platform engagement is very low, we also display statistics for the group of employees (less than $40 \%$ of user accounts) who had logged in at least once on NASA@WORK during the six months before the experiment. We used this variable for the randomized stratification. Overall, employee type does not differ systematically between the general population of platform users and the subset of more recently active ones. Recent activity does differ somewhat by center affiliation. We control for center affiliation in the analysis.

[Insert Table 1 here]

\section{STUDY 1: FIELD EXPERIMENT}

\section{Experimental Design}

We use a natural field experiment (Harrison \& List, 2004) to evaluate the effectiveness of nonfinancial incentives. Subjects were randomly exposed to different interventions and their behavior was not affected by an awareness of the research project. With our field partners, we identified two main classes of non-financial incentives that are theoretically interesting and practically important to study: three forms of recognition, which vary the audience of recognition (manages, peers, or online platform participants), and a message of how platform engagement contributes to the organizational mission. As is often done in studies on behavioral interventions, we also tested the effect of merely providing information about the platform's effectiveness. These five experimental arms were compared to a control group that received a generic reminder email about NASA@WORK. The text for the control group read:

“Greetings, [Name]!

Thanks for being part of the NASA@WORK community. The NASA@WORK ideation platform allows us to draw on the creative minds across the entire Agency to make wonderful things happen! Challenge Owners who identify issues and bring the Challenge process to fruition are crucial since the best solutions can only be as good as the underlying problems they address. 
[Specific statements pertaining to each treatment were inserted here.]

Come explore some of our latest Challenges [hyperlink to NASA@WORK]. Or maybe you want to become a Challenge Owner yourself! If this piques your interest, here are 5 simple steps [hyperlink] to make the most out of Owning your Challenge.

Please don't hesitate to ask if you have any questions. We are happy to have you as part of the NASA@WORK community.”

This text provides a conservative benchmark as our field partners hoped to motivate as many users as possible to engage with the platform; even the email sent to the control group was designed to maximize the number of returns. Specific statements pertaining to each treatment were not visible without opening the email.

Employees in the managerial recognition condition read that their managers would receive “official letters that highlight their leadership and the other skills they demonstrate”. The text was accompanied by a photo of a sample letter sent to managers. Employees in the peer recognition condition were informed that they would receive a NASA@WORK pin and a letter of appreciation from the NASA@WORK team. A photo of the pin and certificate were shown together with this text. In what we call the platform recognition arm, employees were informed that they would "be inducted in the newly created [hyperlinked] NASA@WORK Wall of Fame and recognized in the NASA@WORK Monthly Bulletin and in our tweets”. This was accompanied by a photo of the NASA@WORK bulletin. As for the message about the organizational mission, which we developed jointly with our field partners, we borrowed language from NASA’s most recent Strategic Plan. Employees in the mission condition read:

“Contributing to the platform enables all of us to reaffirm NASA's vision to reach for new heights and reveal the unknown so that what we do and learn will benefit all humankind. It allows us to accomplish our mission to drive advances in science, technology, aeronautics, and space exploration to enhance knowledge, education, innovation, economic vitality, and stewardship of Earth.” 
For exploratory purposes, we also combined statements concerning mission and each of the three recognition treatments, knowing that the increase in length of the email would dilute the recognition component and limit their comparability to the other treatments and control.

Finally, subjects receiving information about the platform’s effectiveness read that: “About $80 \%$ of the Challenges run on this platform have been or are about to be implemented, leading to significant advances and savings for NASA.” Figure A1 in the online appendix shows the screenshots of treatment and control emails.

From the overall pool of 16,806 employees who had a registered NASA@WORK account, 11,192 users were randomized into the five main treatment arms and control group, and 5,674 users were randomly allocated into the three exploratory conditions. ${ }^{1}$ Our analysis focuses on the five main treatment arms, but including all eight treatment arms does not change the results (see Table A2 in the online appendix). As stated in the pre-registration (AEARCTR-0002314), we used a stratified randomization procedure, blocking on (1) recent platform engagement (whether the user had been active in the six months prior to the randomization) and (2) employment status (civil servant or contractor). The CoECI manager delivered the interventions via email, the main channel of communication about the platform. The emails were sent on October 11, 2017.

\section{Analysis and Results}

Table A1 in the online appendix presents a randomization check for the observable user characteristics (employment status, past activity, center affiliation). As expected, before the intervention, the differences are all negligible, point into different directions, and are not statistically significant.

\footnotetext{
${ }^{1}$ As specified in the pre-registration (AEARCTR-0002314), we excluded some groups of users before the randomization: "Data management rules have been set up to drop certain user groups from the list before the randomization: duplicate accounts (the ones with the lower ID\# are dropped as lower ID\#s indicate older accounts), users with InnoCentive domains [employees of the platform operator who merely test the platform], users who are part of the NASA@work/CoECl team (list was provided by field partner) [who operate and manage the platform from within NASA], users without name fields, users lacking name and center affiliation information, users who are identified as interns (as these are transitory accounts)."
} 
In line with our field partners’ goal of increasing NASA@WORK use, our primary outcome of interest, platform engagement, is a binary variable indicating whether a user logged into the platform in the week following treatment delivery. Importantly, the content populated on the platform (e.g., whether there is a challenge for which a given user has the interest or relevant expertise) at the time of the experiment does not confound this measure. The one-week horizon afforded subjects sufficient flexibility in allocating their time across the different days of the week. Since the baseline level of posting on the platform is extremely low, we limit the quantitative analysis to this extensive margin analysis. Study 2 explores implications on the intensive margin, such as users’ perceptions of posting challenges and ideas. We use an intent-to-treat analysis to be conservative and because reliable data on who opened the treatment emails was not available.

We use a conditional logistic regression model with center-level fixed effects to predict platform engagement from the experimental treatments. We add controls for the four strata used in the experimental design, crossing employment status with whether or not the user had logged in during the six months before the experiment. We also control for the number of challenges the user had previously owned (challenges owned) and solved (challenges resolved). Standard errors are clustered by center (affiliation).

In the week after treatment delivery, 682 users, or about $4 \%$ of all users, engaged with the NASA@WORK platform. On average, 77 users logged in across the eight treatments, ranging from 98 (managerial recognition) to 59 (mission and platform recognition).

The regression results are reported in Table 2. The incentive of receiving managerial recognition had a significant positive effect on subsequent platform engagement. Compared to the baseline condition, the message about potential managerial recognition increased the odds of returning to the platform by about $44 \%(\mathrm{OR}=1.443$, RSE $=0.197, p$-value $=0.007)$, controlling for other factors such as prior platform engagement. The results for the other treatments are statistically insignificant. These findings hold also in the most basic model without any controls.

[Insert Table 2 here] 


\section{Discussion of Experimental Findings}

Our field experiment finds that the prospect of managerial recognition had a significant and positive effect on subsequent platform engagement. Study 2 explores the mechanisms behind this effect. The field experiment does not find support for the effectiveness of the other incentives, which may be due to the generally very low platform engagement that made robust quantitative analyses difficult. This relates to a point made by Kane \& Ransbotham (2016) about researching innovation communities: the importance of accounting for a community’s "life stage” when studying and intervening in its collaboration (p. 1259). It also suggests that there are important restraining forces that would first need to be addressed before positive but relatively subtle incentives can work (Lewin, 1951). We therefore conducted a second study, which uses a large number of interviews with NASA employees to explore perceptions of platform engagement, and how these views interact with incentives.

\section{STUDY 2: INTERVIEWS}

Combining quantitative results with qualitative data allows for a more robust analysis and deeper understanding of meaning and context than when using a single method (Fine \& Elsbach, 2000; Ivankova, Creswell, \& Stick, 2006). We conducted follow-on interviews to build on our quantitative findings that illuminated causal effects of incentives for platform engagement and to capture relevant and rich mechanisms of social processes.

\section{Study Design}

To obtain a representative range of reactions, we purposively sampled (Berg, 2001) the initial list of potential informants based on their prior activities on NASA@WORK (posted a challenge, posted solutions, both, or none), employment status (civil servant or contractor), and center affiliation. This method ensured inclusion of individuals displaying diverse characteristics. We invited sampled individuals to participate in an interview via email and conducted all our interviews using Zoom, a video 
conferencing software. We then used snowball sampling (Berg, 2001) to increase our sample. At the end of each interview, we asked the informant for names and contact information of other possible informants. This method warranted us a good introduction, especially to those who are otherwise difficult to reach (e.g., people who have a log-in but haven’t posted anything).

In the initial round of interviews, we focused on understanding the results of the field experiment by eliciting interviewees' perceptions of and experiences with the platform. Why was managerial recognition as effective in inducing platform engagement? Why hadn't other incentives produced similar effects? What did they perceive to be the costs and benefits of engaging with NASA@WORK? In hearing responses to these questions, we noticed that informants' experiences relating to NASA@WORK varied by whether their job was directly or indirectly tied to the organizational mission. To analyze whether these were important factors in understanding incentives for engagement with new innovation mechanisms, we updated the interview protocol with specific questions about distinctions concerning job proximity to mission. With the updated protocol, we intentionally included more employees in administrative roles in our outreach sample for the second round of interviews. (See Appendix 1 for the Interview Protocol.) We continued our interviews until it appeared that we reached the point of theoretical saturation, or when additional interviews did not reveal any new information (Glaser \& Strauss, 1967). We reanalyzed all of the interview transcripts and notes after completing the second round of data collection.

Our final interview sample comprised a total of 53 NASA employees. We conducted 26 interviews in the first round and 27 interviews in the second round. The interviews averaged 34 minutes each and ranged from 19 to 54 minutes. All interviews were digitally recorded (with permission) and subsequently transcribed, resulting in more than 500 pages of interview transcripts and notes. Table 3 shows the summary of interviewee characteristics.

[Insert Table 3 here] 


\section{Data Analysis}

The formal analysis of the interview transcripts comprised three main stages of coding (Chamaz, 2010; Lofland, Snow, Anderson, Lofland, 2006). We began with open coding, perusing the transcripts and identifying codes based on language used by informants. We coded informants' statements about their perceptions of NASA@WORK and reactions to the experimental findings. Examples of open codes included “opportunity to step outside your normal daily activities” (a benefit of engagement) and "have to document every single minute of the day” (a perceived barrier). Next, we grouped open codes into more abstract bundles in the second step of axial coding. These categories evolved as we iterated among the data, emerging themes, and existing literature. Examples of axial codes included "extracurricular” (how NASA@WORK is perceived) and “justification of platform use” (an explanation for effectiveness of the managerial recognition incentive). The third stage entailed exploring and integrating the relationship of the abstract codes into a conceptual framework, summarizing how the data fit together and fit with existing theory. The framework was further refined through discussions with colleagues, informants, and CoECI field partners. All forms of coding were conducted within and across the two rounds of data collection. We used NVivo software to store, organize, and analyze the data. Table 4 summarizes the data structure resulting from the analytic process.

[Insert Table 4 here]

\section{Results}

In what follows, we first address the question of how NASA employees perceive engaging with NASA@WORK. While internal, peer-based innovation mechanisms are increasingly being implemented in organizations (e.g., Jung, Blasco, \& Lakhani, 2018; Terwiesch, Mehta, \& Volpp, 2013), employees’ perceived benefits and barriers of participating remain unclear. Based on this context, we then present data about the role of the recognition incentives studied in the field experiment and how employees' job proximity to mission may interact with these incentives. Lastly, we present data that may explain the 
potential ineffectiveness of using organizational mission as an instrumental incentive. Figure 1 depicts the conceptual framework that organizes the findings.

\section{[Insert Figure 1 here]}

\section{Perceptions of NASA@WORK engagement}

Based on informants’ observations and experiences with NASA@WORK, we conceptualize engaging in this newly adopted innovation mechanism as an extracurricular activity that involves an unconventional approach to problem solving for NASA employees. The interviews reveal a high degree of uncertainty around the legitimacy of platform engagement and its support from management.

Extracurricular. Our informants described engaging with NASA@WORK as an extracurricular task, an addition to the "day job” or the "normal workload”. Browsing challenges and contributing solutions were perceived as a "sidebar activity”, distinct from “primary job function”, “main project”, or "real work”. Some informants even expressed concerns that spending time on NASA@WORK would interfere with their required job assignments. One informant said, “It’s kind of a side thing. Like, we'll be doing our normal daily job, and a question will come in. If we have extra time at the end of the day, we might participate.” Others shared that although engaging with NASA@WORK is not part of their daily routine, they are willing to make time for it in order to help solve technical problems that their peers are facing. One informant described the activity as “community service”, and another informant explained, “If there's something that I can do in ten minutes that would take somebody else a day of work, of course I'm gonna do it.”

\section{Uncertainty around legitimacy of platform engagement. Informants indicated that NASA@WORK} introduces a new, unconventional approach to problem solving. These informants expressed skepticism about the newly adopted platform and about publicizing problems and broadly searching for solutions more generally. One informant said, 
"It's quite a foreign thing to a lot of people here, and maybe not something that people in the dominant culture here understand as much. [That culture is]...more hierarchical and more process-oriented. This [NASA@WORK] goes against that dominant culture, because you can ask anybody anything.”

Similar to Lifshitz-Assaf (2018)'s account of tension and fragmentation towards adopting open innovation, our data also illustrate that problem-solving across silos and finding expertise across the agency is unfamiliar and unaccepted for some. Persisting silos among units and centers and reliance on existing knowledge-transfer networks seem to pose a barrier to platform engagement that enables broad, collective problem-solving.

In addition, informants also shared that whether participating in such novel and unfamiliar mechanisms is permitted or not depends on one’s direct manager. Supervisors that consider platform engagement as productive and beneficial support its use, while others that question the value of the platform discourage use and deem engagement as "wasting time”. There often seemed to be significant uncertainty about supervisors’ attitude towards the new platform.

Against this background of uncertainty, platform engagement was seen as supporting the adoption of the novel problem solving process:

"I think it does come down to changing the culture at NASA as a whole, to understand the idea of, 'We can just throw out a question and get input.' NASA centers still have this culture of being cloistered and not interacting with each other. It gets tricky even on an electronic platform to collaborate. There are pockets that do collaborate between the centers, but as a whole, it's not part of the culture to just say, 'Let's just work all together and find expertise from across the agency."”

\section{Mechanisms behind recognition}

Understanding employees’ perception of platform engagement as extracurricular and of uncertain legitimacy helped us interpret our field experimental findings. The experimental results showed that the prospect of managerial recognition induced greater platform engagement than other types of incentives. 
We specify the relevant level of management as one’s immediate supervisor (Detert \& Treviño, 2010). Our qualitative data suggests that managerial recognition encourages participation in two ways: (1) managerial recognition signals legitimacy for spending time on a task (often) unrelated to the prescribed work; (2) managerial attention is highly valued and offers a sense of appreciation for engaging with the new approach to innovation and problem-solving.

Legitimacy of platform engagement. Informants reported that managerial recognition for contributing to NASA@WORK indicates justification for platform engagement, or time spent on an extracurricular activity. One informant suggested that managerial recognition signals legitimacy of platform use:

“There is the feeling that if you're doing NASA@WORK, then you're not doing real work. If you're playing with their challenges as opposed to doing your real job, when everyone's super busy. Why are you making time for that? So if you have management recognition, then it kind of justifies spending your time that way.”

Another informant explained that managers’ acknowledging NASA@WORK activities offers “at the very least, a tacit approval to participate” and with that permission, engaging on NASA@WORK “is not the same as reading the CNN webpage...not like taking a break. You're actually doing something that management sees as valuable.” Thus, managerial recognition appears to validate and encourage platform engagement.

Our qualitative data suggests that the prospect of recognition is attractive only if the underlying achievement is signal-worthy. The chance to be recognized for contributing to NASA@WORK, an activity that is largely alien among the workforce and not clearly endorsed by managers, may not have been sufficiently appealing for employees. With regard to the anticipation of receiving peer recognition by wearing a NASA@WORK pin, one informant explained that because NASA@WORK is not a wellknown, regularly used platform, “if [wearing a NASA@WORK pin] is your top accomplishment that you want to wear a pin over, that's probably not a good sign. I think people are conscious of that.” In parallel, informants also pointed to the unfamiliarity of NASA@WORK in explaining the ineffectiveness of the 
platform recognition incentive. One informant described the hall-of-fame webpage as a "dark corner of the Internet” that does not draw much traffic. Another informant shared that he'd be worried about being presented on a public webpage for engaging in tasks that are "not backed by management”.

Sense of appreciation. Our data suggests that managerial attention offers a visceral sense of appreciation and validation that motivates discretionary and collaborative behavior. NASA@WORK presents an avenue for employees to volunteer time and effort for tasks beyond the job requirement, and to demonstrate enthusiasm and support for colleagues’ work and the community at large. Our informants expressed appreciation for immediate supervisors' affirming words and actions that acknowledge going the extra mile. One informant said,

“You can recognize someone, like, 'Oh, hey, here's a piece of paper. Thanks for your work.' But to have your boss come up to you, shake your hand, and go, 'Look, thank you for all that you do.' It's a really big difference.”

Our data supports the overall notion that employees appreciate recognition that acknowledges adoption of and engagement with the newly introduced problem-solving practices. One informant said, “Just a little bit of recognition goes a long way. ... It provides those people who have that orientation [to brainstorm across discipline lines] a chance to, if you will, raise their hand in a way that demonstrates that commitment, or that interest.”

In addition, our data indicates that while various awards at NASA celebrate innovation and prosocial conduct, these are infrequent and involve formal nominations and a lengthy selection process. Importantly, they do not seem accessible to many in the organization. Although these awards are prestigious and highly coveted, informants also conveyed desire for managers’ words of praise and encouragement. One informant explained,

"It may be like a supply and demand problem. We do have awards that are given out periodically for teams that do great work and we do have annual performance reviews, but maybe just the average Joe at NASA would like to be recognized more.” 
Employees’ desire for attention and commendation from their supervisors, which are more personal compared to the organizational awards, provides a second explanation for the effectiveness of the managerial recognition incentive.

$\underline{\text { Job proximity to mission as a mediator for the effect of recognition }}$

Although NASA’s mission centers on science, technology, aeronautics, and space exploration, less than $65 \%$ of NASA employees are astronauts, scientists, or engineers. The remaining $35 \%$ of the jobs are in administration, accounting, legal, transportation, information technology, and others (NASA 2019). These jobs indirectly contribute to NASA missions. Our interview data suggests that the sense of appreciation and attention by management may be particularly motivating for employees whose job functions are more distant from the mission. Informants with jobs that are only indirectly related to mission shared that contributing to NASA@WORK can demonstrate to the manager that “you're really like an all-star across the entire job description and NASA in general” and that managerial attention offers a "feeling that you're actually playing a role in the organization". One office secretary informant shared, “I’m on the bottom of the totem pole. So I get excited. For almost every project you get a pin or a patch or a sticker. We don't normally get that because we're not really associated with any.” For employees whose routine work is not explicitly tied to the organizational mission but who want to participate in it, NASA@WORK appeared to fulfill that want and to provide a way to be recognized for their commitment.

\section{Using mission as an instrumental incentive}

Using NASA’s mission as an explicit instrumental incentive was not seen to be positively motivating. For employees who are already drawn to and motivated by the organizational mission, the message seems to have been redundant or even provocative. One informant said, "Some percentage of the NASA population may have rolled its eyes and said, 'I'm already pursuing the future in my day job, why do I need to do this other thing?'” Another informant further elaborated, “You don't need to remind me of 
that [the mission]. That's why we're not in the industry making three times our salaries. It's because we want to do the scientific breakthrough, that's what's exciting to us.”

As before, the uncertainty around the value and legitimacy of platform engagement seems to have contributed to the ineffectiveness of the mission treatment. As one informant stated, "When I think of NASA's mission, I think outer space, humans, and science missions way out in the universe. That doesn't really fit with this online platform for problem solving.” Thus, using mission as an instrumental incentive on the intensive margin seemed to be of limited use in a workforce that had selected into the organization based on a strong mission appeal, and for a task whose connection to the overarching mission was not clear.

\section{IMPLICATIONS FOR THEORY AND RESEARCH}

Our findings contribute to the literatures on non-financial incentives, in particular the literatures on awards (Frey \& Gallus 2017a,b) and mission incentives (Cassar \& Meier, 2018), and motivations on peer-based innovation platforms (Jeppesen \& Frederiksen, 2006; Lakhani \& Wolf, 2005). We were able to partner with NASA for this study and are, to the best of our knowledge, the first to run a field experiment in this important context. It is a challenge to study the causal effects of awards in the field, and even more difficult to study different types of recognition at the same time. We do so by focusing on the ex ante effects of recognition and experimentally vary the expected audience: management, immediate peers, or other platform participants.

Our experimental results showed that the prospect of receiving managerial recognition incentivized platform engagement. We did not find support for the effectiveness of the other non-financial incentives. Our interview findings suggest important and novel mechanisms behind recognition: positive signaling about the task’s legitimacy in a context of change and uncertainty, as well as being noticed and appreciated by management in a way that is personal and timely compared to the formal and infrequently awarded organizational honors. While it has been posited that awards can be used to signal organizational and managerial priorities and goals (Gallus \& Frey, 2017), such signaling has so far received only little 
attention in the empirical literature on organizational awards (see Robinson, Gallus, Lee \& Rogers, 2019 for a recent exception). As our findings suggest, for recognition to work, the underlying task needs to be considered signal-worthy.

We also observe potential heterogeneity in employees’ responsiveness to recognition based on their job proximity to the organization’s mission. Managerial recognition seems to be particularly motivating for employees whose day-to-day work is only indirectly tied to the organizational mission (e.g., secretaries). Interestingly, the demand for acknowledgment was not related to the display of superior ability and performance, but rather to the individual's desire to be recognized as a good citizen who seeks to support organizational change.

In a context of uncertainty around the signal-worthiness of platform engagement, peer recognition and platform recognition were ineffective. While peer recognition would have been in line with the newly aspired-to culture of peer-based problem solving, managerial recognition was in line with the established, hierarchy-based organizational culture. Our findings suggest that an incentive scheme that is aligned with the established culture may be needed to blaze the trail towards the new culture and facilitate the desired change process.

We compare recognition to the use of organizational mission as an incentive. Invoking mission as an incentive is theoretically interesting (Carton, 2018; Cassar \& Meier, 2018; Shamir et al., 1993) as well as practically relevant. We chose and designed our non-financial incentives in collaboration with our field partners, who no longer had financial incentives at their disposal and had to seek alternative ways of motivating platform engagement. Our results suggest that using mission as an instrumental incentive may be difficult if workers are already highly mission-motivated. A mere textual reminder produced little behavioral change. This result is in line with Blasco et al. (2019), who found that a mission-oriented incentive did not effectively motivate hospital employees to contribute ideas towards improving patient care. These results may imply that in organizations such as NASA, hospitals, schools, and others where one presumes mission to provide an important meaning for work, using mission as an explicit and instrumental incentive to further motivate workers on the intensive margin can be limited or even 
counterproductive when it risks being perceived as disingenuous. Moreover, it is possible that without a proper explanation, employees in our context struggled to see the connection between the specific task of platform engagement and the high-level, organizational aspirations (Carton, 2018).

Future work could usefully draw on experiments on more active innovation platforms to analyze these mechanisms as well as the effects of recognition and mission incentives on the frequency and quality of postings. It should moreover explore the boundary conditions to our findings. For instance, we believe that our findings about the importance of managerial appreciation would extend to other organizations adopting inner-organizational innovation platforms. On the other hand, managerial recognition may be less effective to foster engagement with established peer innovation platforms that are already legitimate in the views of employees. Instead, in these cases we would expect peer recognition to be more effective.

\section{IMPLICATIONS FOR PRACTICE}

This study suggests several steps from which organizations may benefit when trying to encourage use of new and peer-based innovation platforms. First, our analysis of non-financial incentives points to the importance of managerial recognition for employees. In line with our findings, a recent Gallup workplace survey found that employees identified the source of their "most memorable recognition” as that from their direct manager, followed by senior leaders, customers, and peers (Mann \& Dvorak, 2016). Our data indicate that employees appreciate managerial attention and appreciation-a low-cost activity that can have significant positive effects. Accordingly, signaling organizational support and training supervisors and middle managers to validate and recognize the contributions of their staff may be critical.

The main mechanism driving our findings is that for recognition incentives to be effective, the underlying task needs to be signal-worthy. This is particularly important in contexts where organizations seek to implement novel initiatives. We expect our results about the importance of managerial recognition in providing appreciation and signaling legitimacy to generalize to contexts of change management and engagement with intra-organizational online platforms more broadly. Paying employees to support such 
new initiatives is most likely ineffective, infeasible, and can even be counterproductive. Instead, offering appreciation by management seems to be a promising avenue. Such appreciation need not be focused on outstanding ability, creativity or performance, but instead may be particularly motivating for employees who make an effort to engage with novel initiatives and support the organization's change. 


\section{REFERENCES}

Amabile TM (1996) Creativity in Context (Westview Press, Boulder, CO).

Amabile TM (1998) How to kill creativity. Harvard Business Review 76(5): 76-87.

Bateman, TS, O’Neill H, Kenworthy-U’Ren A. (2002). A Hierarchical Taxonomy of Top Managers' Goals. Journal of Applied Psychology 87(6):1134-1148.

Berg, BL (2001) Qualitative Research Methods for the Social Sciences (Allyn \& Bacon, Needham Heights, MA). 4th edition.

Bitektine A, Haack P (2015) The "macro" and the "micro" of legitimacy: Toward a multilevel theory of the legitimacy process. Academy of Management Review 40(1):49-75.

Blasco A, Jung OS, Lakhani KR, Menietti M (2019) Incentives for public goods inside organizations: Field experimental evidence. Journal of Economic Behavior \& Organization 160:214-229.

Boudreau KJ, Lacetera N, Lakhani KR (2011) Incentives and Problem Uncertainty in Innovation Contests: An Empirical Analysis. Management Science 57(5):843-863.

Bradler C, Dur R, Neckermann S, Non A (2016) Employee Recognition and Performance: A Field Experiment. Management Science 62(11):iv-vi, 3085-3391.

Burbano VC (2016) Social Responsibility Messages and Worker Wage Requirements: Field Experimental Evidence from Online Labor Marketplaces. Organization Science 27(4):801-1064.

Carton AM (2018) “I'm Not Mopping the Floors, I'm Putting a Man on the Moon”: How NASA Leaders Enhanced the Meaningfulness of Work by Changing the Meaning of Work. Administrative Science Quarterly 63(2):323-369.

Cassar L, Meier S (2018) Nonmonetary Incentives and the Implications of Work as a Source of Meaning. Journal of Economic Perspectives 32(3):215-38.

Chamaz, K (2010). Constructing Grounded Theory: A Practical Guide Through Qualitative Analysis (Sage Publications, Thousand Oaks, CA).

Dahlander L, Piezunka H (2014) Open to suggestions: How organizations elicit suggestions through proactive and reactive attention. Research Policy 43(5):812-827.

Detert JR, Treviño LK (2010) Speaking Up to Higher-Ups: How Supervisors and Skip-Level Leaders Influence Employee Voice. Organization Science 21(1):249-270.

Dur R (2009) Gift Exchange in the Workplace: Money or Attention? Journal of the European Economic Association 7(2-3):550-560.

Edmondson AC, McManus SE (2007) Methodological Fit in Management Field Research. Academy of Management Review 32(4):1246-1264.

Fine G, Elsbach KD (2000) Ethnography and Experiment in Social Psychological Theory Building: Tactics for Integrating Qualitative Field Data with Quantitative Lab Data. Journal of Experimental Social 
Psychology 36:51-76.

Fine GA, Hallett T (2014) Group cultures and the everyday life of organizations: interaction orders and meso-analysis. Organization Studies 35(12):1773-1792.

Frey BS (2007) Awards as compensation. European Management Review 4(1):6-14.

Frey BS, Gallus J (2017a) Honours versus Money: The Economics of Awards. Oxford, UK: Oxford University Press.

Frey BS, Gallus J (2017b) Towards an economics of awards. Journal of Economic Surveys 31(1):190200.

Gallus J (2017) Fostering Public Good Contributions with Symbolic Awards: A Large-Scale Natural Field Experiment at Wikipedia. Management Science 63(12):3999-4015.

Gallus J, Frey BS (2016) Awards: A strategic management perspective. Strategic Management Journal 37(8):1699-1714.

Gallus J, Frey BS (2017) Awards as Strategic Signals. Journal of Management Inquiry 26(1):76-85.

Glaser BG, Strauss AL (1967) The Discovery of Grounded Theory (Aldine Publishing Company, Thousand Oaks, CA).

Gubler T, Larkin I, Pierce L (2016) Motivational spillovers from awards: Crowding out in a multitasking environment. Organization Science 27(2):233-504.

Halac M, Prat A (2016) Managerial Attention and Worker Performance. American Economic Review 106(10):3104-32.

Hammond, M (2000) Communication within on-line forums: the opportunities, the constraints and the value of a communicative approach. Computers \& Education 35(4) 251-262.

Harrison GW, List JA (2004) Field Experiments. Journal of Economic Literature 42(4):1009-1055.

Hedblom D, Hickman BR, List JA (2016) Toward an Understanding of Corporate Social Responsibility: Theory and Field Experimental Evidence.

von Hippel E (2017) Free Innovation by Consumers-How Producers Can Benefit: Consumers' free innovations represent a potentially valuable resource for industrial innovators. Research-Technology Management 60(1):39-42.

Huberman BA, Romero DM, Wu F (2009) Crowdsourcing, attention and productivity. Journal of Information Science 35(6):758-765.

Ivankova, N, Creswell J, Stick S (2009) Using Mixed-Methods Sequential Explanatory Design: From Theory to Practice. Field Methods 18(1) 3-20.

Jeppesen L, Frederiksen L (2006) Why Do Users Contribute to Firm-Hosted User Communities? The Case of Computer-Controlled Music Instruments. Organization Science 17(1). 
Jeppesen L, Lakhani KR (2010) Marginality and Problem-Solving Effectiveness in Broadcast Search. Organization Science 21(5):1016-1033.

Jung OS, Blasco A, Lakhani KR (2018) Innovation contest: Effect of perceived support for learning on participation. Health Care Management Review. Forthcoming.

Kahn WA (1990) Psychological Conditions of Personal Engagement and Disengagement at Work. Academy of Management Journal 33(4):692-724.

Kane GC, Ransbotham S (2016) Content as Community Regulator: The Recursive Relationship Between Consumption and Contribution in Open Collaboration Communities. Organization Science 27(5):12581274.

Kimberly JR, Evanisko MJ (1981) Organizational Innovation: the Influence of Individual, Organizational, and Contextual Factors on Hospital Adoption of Technological and Administrative Innovations. Academy of Management Journal 24(4):689-713.

Kosfeld M, Neckermann S (2011) Getting More Work for Nothing? Symbolic Awards and Worker Performance. American Economic Journal: Microeconomics 3(3):86-99.

Lakhani KR, Wolf R (2005) Why Hackers Do What They Do: Understanding Motivation and Effort in Free/Open Source Software Projects. Feller J, Fitzgerald B, Hissam SA, Lakhani KR, eds. Perspective on Free and Open Software. (MIT Press, Cambridge, MA), 3-23.

Latané B, Williams K, Harkins S (1979) Many hands make light the work: The causes and consequences of social loafing. Journal of Personality and Social Psychology 37(6):822-832.

Lerner J, Tirole J (2002) Some Simple Economics of Open Source. The Journal of Industrial Economics 50(2):197-234.

Levine SS, Prietula MJ (2014) Open Collaboration for Innovation: Principles and Performance.

Organization Science 25(5):1287-1571.

Lewin K (1951) Cartwright D, eds. Field theory in social science; selected theoretical papers (Harper \& Row, New York).

Lifshitz-Assaf H (2018) Dismantling Knowledge Boundaries at NASA: The Critical Role of Professional Identity in Open Innovation. Administrative Science Quarterly 63(4):746-782.

Lofland J, Snow D, Anderson L, Lofland LH (2005) Analyzing Social Settings: A Guide to Qualitative Observation and Analysis (Wadsworth Thompson, Belmont, CA).

Majchrzak A, Cooper LP, Neece OE (2004) Knowledge Reuse for Innovation. Management Science 50(2):174-188.

Mann A, Dvorak N (2016) Employee Recognition: Low Cost, High Impact. Gallup. Accessed May 19, 2019, https://www.gallup.com/workplace/236441/employee-recognition-low-cost-high-impact.aspx.

Piezunka H, Dahlander L (2019) Idea Rejected, Tie Formed: Organizations’ Feedback on Crowdsourced Ideas. Academy of Management Journal 62(2):503-530. 
Restivo M, van de Rijt A (2012) Experimental Study of Informal Rewards in Peer Production. PloS one 7(3):e34358.

Restivo M, van de Rijt A (2014) No praise without effort: experimental evidence on how rewards affect Wikipedia’s contributor community. Information, Communication \& Society 17(4):451-462.

Robinson C, Gallus J, Lee M, Rogers T (2019) The Demotivating Effect (and Unintended Message) of Awards. Organizational Behavior and Human Decision Processes. Forthcoming.

Rossman G, Schilke O (2014) Close, But No Cigar: The Bimodal Rewards to Prize-Seeking. American Sociology Review 79(1):86-108.

Schilke O (2018) A micro-institutional inquiry into resistance to environmental pressures. Academy of Management Journal 61(4):1566.

Shamir B, House RJ, Arthur MB (1993) The motivational effects of charismatic leadership: A selfconcept based theory. Organization Science 4(4):577-594.

Shils E (1975) Center and Periphery: Essays in Macrosociology (University of Chicago Press, Chicago).

Terwiesch C, Mehta SJ, Volpp KG (2013) Innovating in Health Delivery: the Penn Medicine Innovation Tournament. Healthcare 1:37-41.

Thaler RH, Sunstein CR (2008) Nudge: Improving decisions about health, wealth, and happiness (Yale University Press, New Haven, CT).

Vaughn D (1996) The Challenger Launch Decision: Risky Technology, Culture, and Deviance at NASA (University of Chicago Press, Chicago, IL).

Vaughn D (2006) NASA revisited: Theory, analogy, and public sociology. American Journal of Sociology 112:353-393.

Weber M (1978) Roth G, Wittich C eds. Economy and Society: An Outline of Interpretive Sociology (University of California Press, Berkeley).

Zhang X, Bartol KM (2010) Linking empowering leadership and employee creativity: The influence of psychological empowerment, intrinsic motivation, and creative process engagement. Academy of Management Journal 53(1):107-128.

Zhang XM, Zhu F (2011) Group size and incentives to contribute: A natural experiment at Chinese Wikipedia. American Economic Review 101(4):1601-1615. 


\section{TABLES \& FIGURES}

Table 1. Description of NASA@WORK Population and Engagement

Table 2. Logistic Regression Models Predicting Platform Engagement

Table 3. Interview Sample Characteristics

Table 4. Overview of Qualitative Data Structure

Figure 1. Conceptual Framework

Appendix 1. Interview Protocol for Semi-Structured Interviews

Table A1. Balance Table of User Characteristics by Treatment Assignment

Table A2. Logistic Regression Models Predicting Platform Engagement Including Exploratory Arms

Table A3. Logistic Regression Models Exploring Treatment Effects on Contractors

Figure A1. Screenshots of treatment emails 
Table 1. Description of NASA@WORK Population and Engagement

\begin{tabular}{|c|c|c|c|c|}
\hline & $\begin{array}{c}\text { NASA@WORK } \\
\text { population } \\
\text { N (\%) }\end{array}$ & $\begin{array}{c}\text { Challenge } \\
\text { Owner }^{1} \\
\mathrm{~N}(\%)\end{array}$ & $\begin{array}{c}\text { Challenge } \\
\text { winner } \\
\mathrm{N}(\%)\end{array}$ & $\begin{array}{c}\text { Logged in at } \\
\text { least once } 6 \\
\text { months prior to } \\
\text { the experiment } \\
N(\%)\end{array}$ \\
\hline \multicolumn{5}{|c|}{ Employment status } \\
\hline Civil servant & 8,609 (51) & $95(94)$ & $110(63)$ & $3,422(51)$ \\
\hline Contractor & 8,197 (49) & $6(6)$ & $64(37)$ & 3,263 (49) \\
\hline \multicolumn{5}{|c|}{ Center affiliation } \\
\hline AFRC & $264(1.6)$ & $0(0)$ & $5(2.9)$ & $109(1.6)$ \\
\hline ARC & $634(3.8)$ & $2(2.0)$ & $10(5.7)$ & $248(3.7)$ \\
\hline GRC & $1,455(8.7)$ & $3(3.0)$ & $13(7.5)$ & $519(7.8)$ \\
\hline GSFC & $1,572(9.3)$ & $7(6.9)$ & $12(6.9)$ & $517(7.7)$ \\
\hline $\mathrm{HQ}$ & $577(3.4)$ & $6(5.9)$ & $6(3.4)$ & $174(2.6)$ \\
\hline JSC & $4,734(28)$ & $53(52)$ & $74(43)$ & $2,085(31)$ \\
\hline KSC & $2,666(16)$ & $9(8.9)$ & $15(8.6)$ & 1,137 (17) \\
\hline LARC & $1,324(7.9)$ & $6(5.9)$ & $10(5.7)$ & $609(9.1)$ \\
\hline MSFC & $2,019(12)$ & $8(7.9)$ & $13(7.5)$ & $746(11)$ \\
\hline SSC & $331(2.0)$ & $3(3.0)$ & $4(2.3)$ & $134(2.0)$ \\
\hline WSTF & $123(0.7)$ & $1(1.0)$ & $2(1.1)$ & $47(0.7)$ \\
\hline Other ${ }^{2}$ & $1,107(6.6)$ & $3(3.0)$ & $10(5.7)$ & $360(5.4)$ \\
\hline Total & 16,806 & $101(0.6)$ & $174(1.0)$ & $6,685(40)$ \\
\hline
\end{tabular}

Note. AFRC: Armstrong Flight Research Center; ARC: Ames Research Center; GRC: Glenn Research Center; GSFC: Goddard Space Flight Center; HQ: Headquarters; JSC: Johnson Space Center; KSC: Kennedy Space Center; LARC: Langley Research Center; MSFC: Marshall Space Flight Center; SSC: Stennis Space Center; WSTF: White Sands Complex/Test Facility

${ }^{1}$ To be a challenge owner, one must be a civil servant; contractors can co-own challenges with a civil servant partner.

${ }^{2}$ Other includes Brad, Dale, Dryden Flight Research Center, Goddard Institute for Space Studies, Independent Verification and Validation, Jet Propulsion Laboratory, Michoud Assembly Facility, NASA Shared Services Center, and Wallops Flight Facility. 
Table 2. Logistic Regression Models Predicting Platform Engagement

\begin{tabular}{lcccccc}
\hline & \multicolumn{3}{c}{ Model 1 } & \multicolumn{2}{c}{ Model 2 } & \multicolumn{2}{c}{ Model 3 } \\
\cline { 2 - 7 } & \multicolumn{2}{c}{ Dependent variable } & log-in within one week of intervention \\
\cline { 2 - 7 } & OR & RSE & OR & RSE & OR & RSE \\
\hline Treatments & $1.433^{*}$ & 0.205 & $1.433^{* *}$ & 0.201 & $1.443^{* *}$ & 0.197 \\
$\quad$ Managerial recognition & 1.322 & 0.265 & 1.319 & 0.275 & 1.331 & 0.274 \\
$\quad$ Peer recognition & 0.915 & 0.160 & 0.900 & 0.157 & 0.911 & 0.150 \\
$\quad$ Platform recognition & 0.900 & 0.215 & 0.891 & 0.215 & 0.900 & 0.213 \\
$\quad$ Mission & 1.134 & 0.126 & 1.121 & 0.126 & 1.134 & 0.121 \\
$\quad$ Information & Not included & Included & Included \\
Center-level fixed effects & Not included & Included & Included \\
Stratification variables & Not included & Not included & Included \\
Control variables & \multicolumn{2}{c}{$-1,927$} & $-1,849$ & $-1,845$ \\
Log likelihood & \multicolumn{2}{c}{11,192} & & 11,147 & 11,147 \\
Observations & & &
\end{tabular}

Notes. An odds ratio (OR) less than 1 indicates lower platform engagement than in the control group, which received the baseline email with no treatment; conversely, an OR greater than 1 indicates higher platform engagement than in the control group. Standard errors are clustered by center affiliation. Stratification variables are employment status (civil servant or contractor) and prior activity (logged in within the 6 months before the experiment). In models 2 and 3, 45 observations (i.e., users in 4 centers) are dropped because of all positive or negative outcomes within a center. The main specification (model 3) adds control variables for the number of previously owned and solved challenges. Correcting for multiple hypothesis testing using the Bonferroni method does not meaningfully change the results. The $p$-value on the managerial recognition coefficient in the main specification becomes 0.036 .

$* p<0.05 ;{ }^{* *} p<0.01$ 


\begin{tabular}{|c|c|c|c|c|c|}
\hline & \multicolumn{4}{|c|}{ Engagement with NASA@WORK } & \multirow[b]{2}{*}{ Total } \\
\hline & $\begin{array}{l}\text { Owned a } \\
\text { challenge }\end{array}$ & $\begin{array}{c}\text { Contributed } \\
\text { to a } \\
\text { challenge }\end{array}$ & $\begin{array}{c}\text { Owned \& } \\
\text { contributed } \\
\text { a challenge }\end{array}$ & None & \\
\hline No. of Interviews & 10 & 21 & 10 & 12 & 53 \\
\hline $\begin{array}{l}\text { Civil servant/contractor } \\
\text { Job proximity to mission }\end{array}$ & \multicolumn{4}{|c|}{ Job proximity to mission } & $37 / 16$ \\
\hline Close (e.g., engineer, scientist) & 9 & 12 & 7 & 10 & 38 \\
\hline Distant (e.g., administration) & 1 & 9 & 3 & 2 & 15 \\
\hline Female/male & $6 / 4$ & $4 / 17$ & $2 / 8$ & $4 / 8$ & $16 / 37$ \\
\hline \multicolumn{6}{|l|}{ Organizational tenure } \\
\hline Less than 5 years & 2 & 2 & 1 & 2 & 7 \\
\hline $5-10$ years & 4 & 7 & 2 & 2 & 15 \\
\hline $10-20$ years & 3 & 6 & 2 & 3 & 14 \\
\hline $20+$ years & 1 & 6 & 5 & 5 & 17 \\
\hline \multicolumn{6}{|l|}{ Center affiliation } \\
\hline Ames Research Center & 1 & 1 & 0 & 2 & 4 \\
\hline Armstrong Flight Research Center & 0 & 2 & 0 & 0 & 2 \\
\hline Glenn Research Center & 0 & 1 & 0 & 0 & 1 \\
\hline Goddard Space Flight Center & 1 & 2 & 1 & 2 & 6 \\
\hline Headquarters & 1 & 1 & 1 & 0 & 3 \\
\hline Johnson Space Center & 5 & 6 & 4 & 6 & 21 \\
\hline Kennedy Space Center & 1 & 2 & 3 & 1 & 7 \\
\hline Langley Research Center & 0 & 1 & 0 & 0 & 1 \\
\hline Marshall Space Flight Center & 1 & 2 & 0 & 1 & 4 \\
\hline NASA Shared Services Center & 0 & 1 & 0 & 0 & 1 \\
\hline Stennis Space Center & 0 & 1 & 1 & 0 & 2 \\
\hline White Sands Test Facility & 0 & 1 & 0 & 0 & 1 \\
\hline
\end{tabular}


Table 4. Overview of Qualitative Data Structure

\begin{tabular}{|c|c|c|}
\hline Topics & Axial code & Open code examples \\
\hline \multirow[t]{2}{*}{$\begin{array}{l}\text { Perception of } \\
\text { NASA@WORK } \\
\text { engagement }\end{array}$} & $\begin{array}{l}\text { (For workers } \\
\text { with jobs } \\
\text { distant from } \\
\text { mission) }\end{array}$ & $\begin{array}{l}\text { "No one really recognizes that as real work" } \\
\text { "A side thing" } \\
\text { "I think of it as sort of community service" } \\
\text { "An opportunity to step outside your normal daily activities" } \\
\text { "A fun opportunity to get more engaged with NASA missions" }\end{array}$ \\
\hline & Unconventional & $\begin{array}{l}\text { "This [NASA@WORK] goes against that dominant culture, because } \\
\text { you can ask anybody anything" } \\
\text { "It's not part of the culture to just say, 'Let's just work all together, } \\
\text { and find expertise from across the agency.'” } \\
\text { "I probably would exercise other options first before doing that." }\end{array}$ \\
\hline \multirow[t]{2}{*}{$\begin{array}{l}\text { Mechanisms } \\
\text { of recognition } \\
\text { incentives }\end{array}$} & $\begin{array}{l}\text { Legitimacy of } \\
\text { platform } \\
\text { engagement }\end{array}$ & $\begin{array}{l}\text { "Top-down approval would probably help people feel like that it's } \\
\text { permissible" } \\
\text { "Credibility that it's something important" } \\
\text { "You probably would wear the NASA pin... rather than the } \\
\text { NASA@WORK pin" } \\
\text { "If you post my name in the dark corner of the Internet, I do not } \\
\text { necessarily feel very recognized" } \\
\text { "Getting your picture posted on a website... looks like you're not } \\
\text { doing work that's backed by management" }\end{array}$ \\
\hline & $\begin{array}{l}\text { Sense of } \\
\text { appreciation } \\
\text { (For workers } \\
\text { with jobs } \\
\text { distant from } \\
\text { mission) }\end{array}$ & $\begin{array}{l}\text { "Want to feel valued" } \\
\text { "The average Joe at NASA would like to be recognized more" } \\
\text { "If I'm doing great things, unless I'm waving my own flag, there's no } \\
\text { recognition for it" } \\
\text { "Feeling that you're actually playing a role in the organization" } \\
\text { "Provides ... a chance to raise their hand in a way that demonstrates } \\
\text { that commitment, or that interest" }\end{array}$ \\
\hline \multirow[t]{2}{*}{$\begin{array}{l}\text { Mechanisms } \\
\text { of mission } \\
\text { incentive }\end{array}$} & $\begin{array}{l}\text { Redundant } \\
\text { reminder }\end{array}$ & $\begin{array}{l}\text { "I'm already pursuing the mission in my day job; why do I need to do } \\
\text { this other thing?" } \\
\text { "Don't need to remind me of that. That's why we're not in the } \\
\text { industry making three times our salaries" }\end{array}$ \\
\hline & $\begin{array}{l}\text { Unclear } \\
\text { relationship to } \\
\text { platform }\end{array}$ & $\begin{array}{l}\text { "How is NASA@WORK going to really influence any sort of mission?" } \\
\text { "Outer space, humans, and science missions...doesn't really fit with } \\
\text { this online platform for problem solving." }\end{array}$ \\
\hline
\end{tabular}


Figure 1. Conceptual Framework

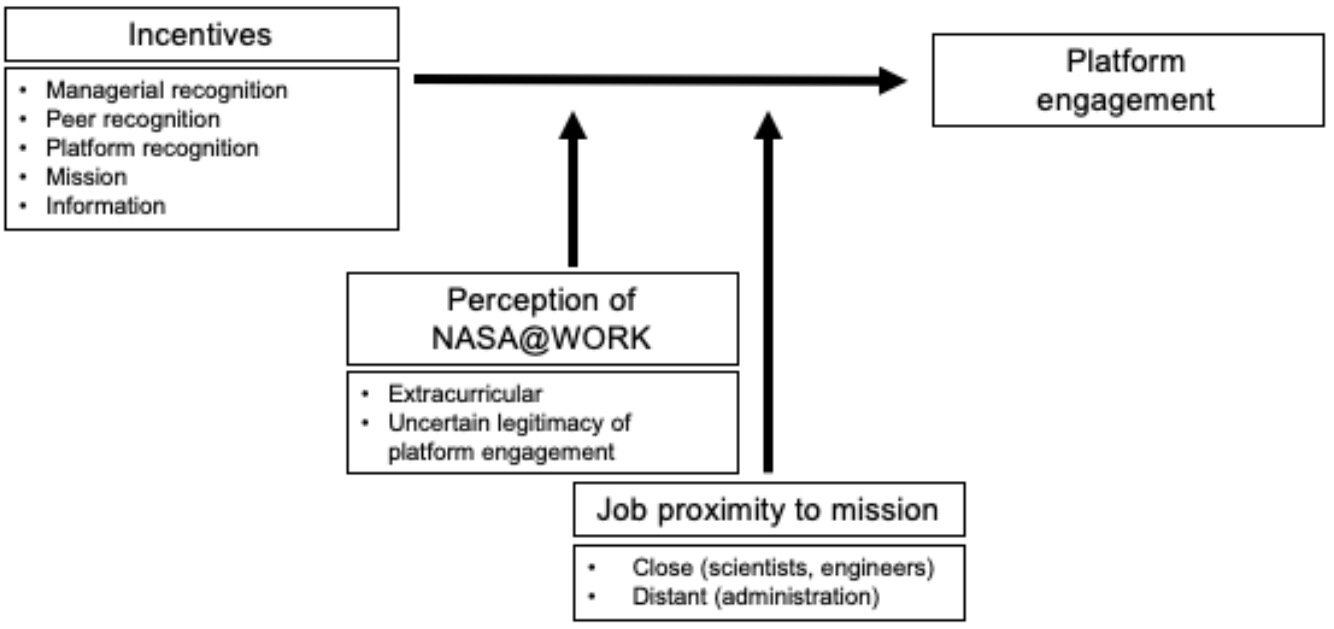




\section{Appendix 1. Interview Protocol for Semi-Structured Interviews}

Introductions

- Can you tell me about your role/job at NASA?

- How long have you worked at NASA?

- Which center are you a part of?

\section{Experience with NASA@WORK}

- Can you describe the extent of your engagement with NASA@WORK?

- How often do you visit the platform in a given week or month? What prompts you to visit the platform?

[If posted a challenge and/or a solution]

- What motivated you to post?

- How much time did you spend on the platform?

- Did you connect with people about the question you posted outside of the platform? If so, could you tell me more about this experience?

[If posted a challenge but not a solution]

- Did you find submitted ideas to be helpful? Did anything surprise you?

- What would you describe as the main barrier(s) for not posting a solution?

[If posted a solution but not a challenge]

- Have you ever considered owning a challenge? Why or why not?

[If haven't posted a challenge or a solution]

- What would you describe as the main barrier(s) for your limited engagement?

- What would motivate you to use the platform?

\section{General impressions of NASA@WORK}

- What do you see as the main purpose of NASA@WORK?

- What would motivate more people to use the NASA@WORK platform?

- (Added in the updated protocol) Do you think one's role or job at NASA affects the way one approaches and engages with NASA@WORK? Why or why not?

Other activities similar to NASA@WORK at NASA (added in the updated protocol)

- Are there other activities at NASA that are, like NASA@WORK, "pro-social”, as in beneficial for the organization but not immediately beneficial for the person doing it?

- How do employees at NASA get recognized for participating in these types of activities?

- What about for leadership and participation in organizational improvement, more broadly? Do employees at NASA get recognized for participating in these types of activities?

- Can you tell me an example of someone, yourself or a colleague, getting recognized for going above and beyond one's job? 


\section{Reactions to experimental findings}

We emailed all 17,000+ NASA employees registered on NASA@WORK. Each person received one of nine emails, each highlighting a different potential motivator. We wanted to see if highlighting the mission of NASA, effectiveness of the platform, the prospect of getting recognized by managers, getting recognized in front of one's peers/coworkers with a lapel pin, or getting publicly recognized on the NASA@WORK hall of fame webpage would affect people’s engagement with NASA@WORK.

- We found that people who received the email highlighting managerial recognition were most likely to visit NASA@WORK afterwards. Do you have any thoughts about why this might have been the case?

- What about getting a lapel pin that you can wear in front of peers/coworkers?

- What about getting recognized on the NASA@WORK "hall of fame” webpage?

- What about highlighting NASA's mission?

- Would getting an email that highlights the impact of NASA@WORK, saying that " $80 \%$ of the Challenges run on this platform have been or are about to be implemented, leading to significant advances and savings for NASA” impact your engagement with the platform? Why or why not? 
Table A1. Balance Table of User Characteristics by Treatment Assignment

\begin{tabular}{|c|c|c|c|c|c|c|c|c|c|c|}
\hline & \multirow[b]{2}{*}{ Control } & \multicolumn{8}{|c|}{ Treatment assignment } & \multirow[b]{2}{*}{$p$-value } \\
\hline & & (1) & $(2)$ & (3) & (4) & (5) & (6) & (7) & (8) & \\
\hline \multicolumn{11}{|l|}{ A. Stratification variables } \\
\hline \multicolumn{11}{|l|}{ Employment Status } \\
\hline Civil servant & $51.0 \%$ & $51.2 \%$ & $51.2 \%$ & $51.5 \%$ & $51.4 \%$ & $50.9 \%$ & $51.0 \%$ & $51.6 \%$ & $51.1 \%$ & 1.000 \\
\hline Contractor & $49.0 \%$ & $48.8 \%$ & $48.8 \%$ & $48.5 \%$ & $48.6 \%$ & $49.1 \%$ & $49.0 \%$ & $48.4 \%$ & $48.9 \%$ & \\
\hline $\begin{array}{l}\text { Last log-in within } 6 \text { months before the } \\
\text { experiment }\end{array}$ & $39.6 \%$ & $39.9 \%$ & $40.1 \%$ & $40.1 \%$ & $39.8 \%$ & $39.6 \%$ & $39.7 \%$ & $39.5 \%$ & $39.7 \%$ & 1.000 \\
\hline \multicolumn{11}{|l|}{ B. Prior activity on NASA@WORK } \\
\hline Owned a challenge & $0.59 \%$ & $0.54 \%$ & $0.75 \%$ & $0.70 \%$ & $0.75 \%$ & $0.43 \%$ & $0.69 \%$ & $0.48 \%$ & $0.48 \%$ & 0.862 \\
\hline Won a challenge & $1.12 \%$ & $1.02 \%$ & $1.13 \%$ & $0.80 \%$ & $1.13 \%$ & $1.07 \%$ & $0.96 \%$ & $1.07 \%$ & $1.01 \%$ & 0.992 \\
\hline $\begin{array}{l}\text { Days since last log-in at the time of } \\
\text { experiment }\end{array}$ & 545 & 581 & 551 & 553 & 561 & 564 & 556 & 572 & 563 & 0.679 \\
\hline \multicolumn{11}{|l|}{ C. Center affiliation } \\
\hline Armstrong Flight Research Center & $1.12 \%$ & $1.72 \%$ & $1.34 \%$ & $1.45 \%$ & $1.61 \%$ & $1.76 \%$ & $1.82 \%$ & $1.50 \%$ & $1.81 \%$ & 0.705 \\
\hline Ames Research Center & $3.47 \%$ & $4.14 \%$ & $3.97 \%$ & $3.70 \%$ & $4.56 \%$ & $3.42 \%$ & $3.95 \%$ & $3.43 \%$ & $3.31 \%$ & \\
\hline Brad & $0.00 \%$ & $0.00 \%$ & $0.00 \%$ & $0.00 \%$ & $0.00 \%$ & $0.05 \%$ & $0.00 \%$ & $0.00 \%$ & $0.00 \%$ & \\
\hline Dryden Flight Research Center & $0.27 \%$ & $0.27 \%$ & $0.43 \%$ & $0.38 \%$ & $0.43 \%$ & $0.27 \%$ & $0.11 \%$ & $0.37 \%$ & $0.32 \%$ & \\
\hline Dale & $0.00 \%$ & $0.00 \%$ & $0.00 \%$ & $0.00 \%$ & $0.00 \%$ & $0.00 \%$ & $0.05 \%$ & $0.00 \%$ & $0.00 \%$ & \\
\hline Goddard Institute for Space Studies & $0.00 \%$ & $0.00 \%$ & $0.00 \%$ & $0.00 \%$ & $0.00 \%$ & $0.05 \%$ & $0.00 \%$ & $0.05 \%$ & $0.05 \%$ & \\
\hline Glenn Research Center & $9.41 \%$ & $8.34 \%$ & $7.95 \%$ & $9.12 \%$ & $9.17 \%$ & $9.35 \%$ & $8.12 \%$ & $8.46 \%$ & $8.00 \%$ & \\
\hline Goddard Space Flight Center & $10.6 \%$ & $9.10 \%$ & $8.70 \%$ & $9.12 \%$ & $8.90 \%$ & $9.67 \%$ & $9.83 \%$ & $9.43 \%$ & $8.85 \%$ & \\
\hline Headquarters & $3.69 \%$ & $3.66 \%$ & $3.44 \%$ & $3.06 \%$ & $3.16 \%$ & $3.10 \%$ & $3.85 \%$ & $3.05 \%$ & $3.89 \%$ & \\
\hline Independent Verification \& Validation & $0.48 \%$ & $0.65 \%$ & $0.64 \%$ & $0.38 \%$ & $0.21 \%$ & $0.37 \%$ & $0.37 \%$ & $0.48 \%$ & $0.80 \%$ & \\
\hline Jet Propulsion Laboratory & $3.37 \%$ & $2.31 \%$ & $2.36 \%$ & $2.58 \%$ & $2.52 \%$ & $2.40 \%$ & $2.35 \%$ & $2.57 \%$ & $2.19 \%$ & \\
\hline Johnson Space Center & $28.6 \%$ & $27.0 \%$ & $28.2 \%$ & $28.1 \%$ & $28.1 \%$ & $27.4 \%$ & $27.9 \%$ & $30.2 \%$ & $28.1 \%$ & \\
\hline Kennedy Space Center & $15.2 \%$ & $14.8 \%$ & $16.3 \%$ & $16.0 \%$ & $15.2 \%$ & $16.4 \%$ & $17.0 \%$ & $15.9 \%$ & $15.9 \%$ & \\
\hline Langley Research Center & $7.38 \%$ & $9.10 \%$ & $7.20 \%$ & $7.83 \%$ & $7.94 \%$ & $7.85 \%$ & $7.37 \%$ & $7.45 \%$ & $8.80 \%$ & \\
\hline Michoud Assembly Facility & $0.16 \%$ & $0.22 \%$ & $0.48 \%$ & $0.11 \%$ & $0.21 \%$ & $0.27 \%$ & $0.53 \%$ & $0.27 \%$ & $0.32 \%$ & \\
\hline Marshall Space Flight Center & $11.0 \%$ & $12.9 \%$ & $13.8 \%$ & $12.1 \%$ & $11.5 \%$ & $12.0 \%$ & $11.1 \%$ & $11.6 \%$ & $12.2 \%$ & \\
\hline NASA Shared Services Center & $1.44 \%$ & $1.94 \%$ & $1.61 \%$ & $1.93 \%$ & $1.77 \%$ & $1.87 \%$ & $1.50 \%$ & $1.29 \%$ & $1.55 \%$ & \\
\hline
\end{tabular}




$\begin{array}{lccccccccc}\text { Stennis Space Center } & 1.76 \% & 1.56 \% & 2.15 \% & 2.31 \% & 2.41 \% & 1.60 \% & 1.71 \% & 1.93 \% & 2.29 \% \\ \text { Wallops Flight Facility } & 1.39 \% & 1.61 \% & 1.13 \% & 0.97 \% & 1.50 \% & 1.39 \% & 1.71 \% & 1.23 \% & 0.75 \% \\ \text { White Sands Complex } & 0.00 \% & 0.16 \% & 0.05 \% & 0.00 \% & 0.00 \% & 0.05 \% & 0.11 \% & 0.05 \% & 0.05 \% \\ \text { White Sands Test Facility } & 0.69 \% & 0.59 \% & 0.27 \% & 0.86 \% & 0.80 \% & 0.80 \% & 0.59 \% & 0.75 \% & 0.75 \% \\ & & & & & & & & & \\ & 1,871 & 1,858 & 1,862 & 1,864 & 1,865 & 1,872 & 1,872 & 1,867 & 1,875\end{array}$

Note. The last column shows the p-values from a Chi-square test of independence and analysis of variance (ANOVA) between platform user characteristics and treatment assignments. The control group received a reminder email about engaging with NASA@WORK without information about incentives. Main treatments: (1): managerial recognition; (2): peer recognition; (3): platform recognition; (4): mission; (5): information about platform effectiveness. Three exploratory arms: (6): mission \& managerial recognition; (7): mission \& peer recognition; (8): mission \& platform recognition. 
Table A2. Logistic Regression Models Predicting Platform Engagement Including Exploratory Arms

\begin{tabular}{lcccccc}
\hline & \multicolumn{2}{c}{ Model 1 } & \multicolumn{2}{c}{ Model 2 } & \multicolumn{2}{c}{ Model 3 } \\
\cline { 2 - 6 } & \multicolumn{2}{c}{ Dependent variable $=$ log-in within one week of intervention } \\
\cline { 2 - 6 } & OR & RSE & OR & RSE & OR & RSE \\
\hline Treatments & & & & & & \\
$\quad$ Managerial recognition & $1.443^{* *}$ & 0.197 & & & $1.445^{* *}$ & 0.197 \\
$\quad$ Peer recognition & 1.331 & 0.274 & & & 1.340 & 0.273 \\
$\quad$ Platform recognition & 0.911 & 0.150 & & 0.912 & 0.150 \\
$\quad$ Mission & 0.900 & 0.213 & & 0.900 & 0.212 \\
$\quad$ Information & 1.134 & 0.121 & & & 1.134 & 0.121 \\
$\quad$ Mission \& managerial recognition & & & 1.123 & 0.143 & 1.116 & 0.147 \\
$\quad$ Mission \& peer recognition & & & 1.171 & 0.209 & 1.165 & 0.210 \\
$\quad$ Mission \& platform recognition & & & 0.830 & 0.157 & 0.835 & 0.161 \\
Center-level fixed effects & Included & Included & Included \\
Stratification variables & Included & Included & Included \\
Control variables & Included & Included & Included \\
Log likelihood & -1,845 & $-1,139$ & $-2,730$ \\
Observations & 11,147 & 7,420 & 16,742 \\
\hline
\end{tabular}

Notes. An odds ratio (OR) less than 1 indicates lower platform engagement than in the control group, which received the baseline email; conversely, an OR greater than 1 indicates higher platform engagement than in the control group. Standard errors are clustered by center affiliation. Stratification variables are employment status (civil servant or contractor) and prior activity (logged in within the 6 months before the experiment).

$* p<0.05 ; * * p<0.01$ 
Table A3. Logistic Regression Models Exploring Treatment Effects on Contractors

\begin{tabular}{lcccc}
\hline & \multicolumn{2}{c}{ Model 1 } & \multicolumn{2}{c}{ Model 2 } \\
\cline { 2 - 5 } & \multicolumn{2}{c}{$\begin{array}{c}\text { Dependent variable = log-in within } \\
\text { one week of intervention }\end{array}$} \\
\cline { 2 - 5 } & OR & RSE & OR & RSE \\
\hline Treatments & & & & \\
$\quad$ Managerial recognition & $1.443^{* *}$ & 0.197 & 1.170 & 0.205 \\
$\quad$ Peer recognition & 1.331 & 0.274 & 1.144 & 0.279 \\
$\quad$ Public recognition & 0.911 & 0.150 & 0.733 & 0.190 \\
$\quad$ Mission & 0.900 & 0.213 & 0.703 & 0.151 \\
$\quad$ Information on platform impact & 1.134 & 0.121 & 0.820 & 0.224 \\
Treatment x Contractor & & & & \\
$\quad$ Managerial recognition x Contractor & & & $1.511^{*}$ & 0.307 \\
$\quad$ Peer recognition x Contractor & & & 1.355 & 0.405 \\
$\quad$ Public recognition x Contractor & & 1.532 & 0.481 \\
$\quad$ Mission x Contractor & & $1.614^{*}$ & 0.329 \\
$\quad$ Information on platform impact x Contractor & & 1.840 & 0.689 \\
Center-level fixed effects & & Included \\
Stratification variables & Included & Included \\
Control variables & Included & Included \\
Log likelihood & Included & $-1,843$ \\
Observations & $-1,845$ & 11,147 \\
\hline
\end{tabular}

Notes. An odds ratio (OR) less than 1 indicates lower platform engagement than in the control group, which received the baseline email; conversely, an OR greater than 1 indicates higher platform engagement than in the control group. Standard errors are clustered by center affiliation. Stratification variables are employment status (civil servant or contractor) and prior activity (logged in within the 6 months before the experiment).

$* p<0.05 ; * * p<0.01$ 


\section{Figure A1. Screenshots of the Treatment Emails}

\section{Control group}

Thanks for being part of the NASA@work community.

The NASA@work ideation platform allows us to draw on the creative minds across the entire Agency to make wonderful things happen! Challenge Owners who identify issues and bring the Challenge process to frution are crucial since the best solutions can only be as good as the underlying problems they address.

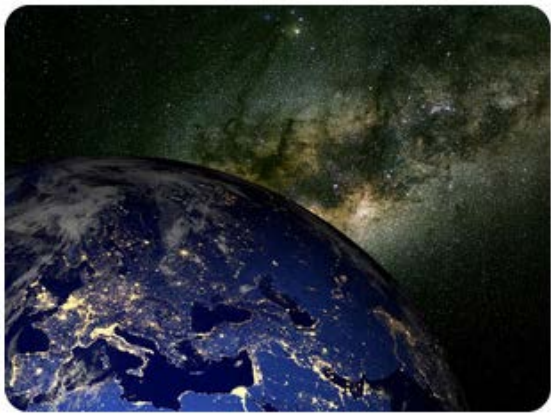

Come explore some of our latest Challenges. Or maybe you want to become a Challenge Owner yourself If this piques your interest, here are 5 simple steps to make the most out of Owning your Challenge.

Please don't hesitate to ask if you have any questions. We are happy to have you as part of the NASA@work community.
T1: Platform effectiveness

Thanks for being part of the NASA@work community.

The NASA@work ideation platform allows us to draw on the creative minds across the entire Agency to make wonderful things happen! Challenge Owners who identify issues and bring the Challeng process to fruition are crucial since the best solutions can only be as good as the underlying problems they address.

About $80 \%$ of the Challenges run on this platform have been or are about to be implemented, leading to significant advances and savings for NASA

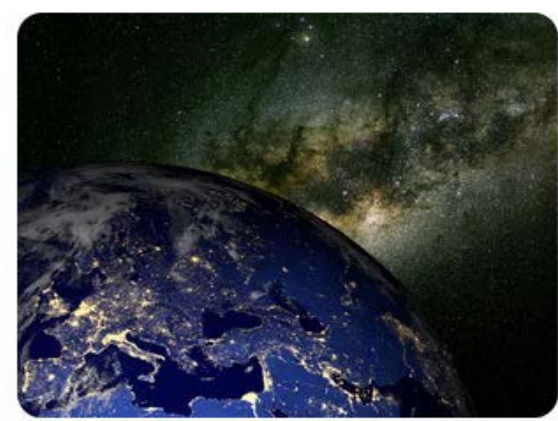

Come explore some of our latest Challenges. Or maybe you want to become a Challenge Owner yourself! If this piques your interest, here are 5 simple steps to make the most out of Owning your Challenge.

Please don't hesitate to ask if you have any questions. We are happy to have you as part of the NASA@work community.
T2: Mission

Thanks for being part of the NASA@work community.

The NASA@work ideation platform allows us to draw on the creative minds across the entire Agency to make wonderful things happen! Challenge Owners who identify issues and bring the Challenge process to fruition are crucial since the best solutions can only be as good as the underlying problems they address.

Contributing to the platform enables all of us to reaffirm NASA's vision to reach for new heights and reveal the unknown so that what we do and learn will benefit all humankind. It allows us to accomplish our mission to drive advances in science, technology, aeronautics, and space exploration to enhance knowledge, education, innovation, economic vitality, and stewardship of Earth

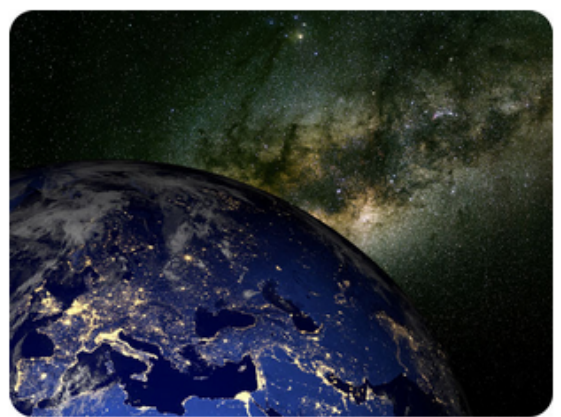

Come explore some of our latest Challenges. Or maybe you want to become a Challenge Owner yourself! If this piques your interest, here are 5 simple steps to make the most out of Owning your Challenge.

Please don't hesitate to ask if you have any questions. We are happy to have you as part of the NASA@work community. 


\section{T3: Peer recognition (i.e., pin)}

Thanks for being part of the NASA@work community.

The NASA@work ideation platform allows us to draw on the creative minds across the entire Agency to make wonderful things happen! Challenge Owners who identify issues and bring the Challenge process to fruition are crucial since the best solutions can only be as good as the underlying problems they address.

This is why we have decided to recognize the Challenge Owners behind our Coolest Challenges. From now on, they will receive our NASA@work pin together with a personal letter of appreciation from the NASA@work team.

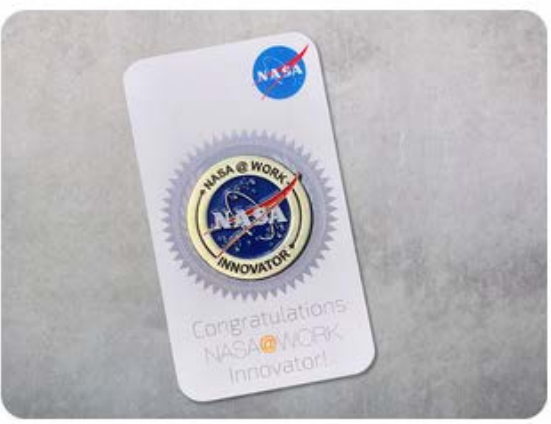

Come explore some of our latest Challenges. Or maybe you want to become a Challenge Owner yourself! If this piques your interest, here are 5 simple steps to make the most out of Owning your Challenge.

Please don't hesitate to ask if you have any questions. We are happy to have you as part of the NASA@work community.

\section{T4: Managerial recognition}

Thanks for being part of the NASA@work community.

The NASA@work ideation platform allows us to draw on the creative minds across the entire Agency to make wonderful things happen! Challenge Owners who identify issues and bring the Challenge process to fruition are crucial since the best solutions can only be as good as the underlying problems they address.

This is why we have decided to recognize the Challenge Owners behind our Coolest Challenges. From now on, we will make their managers aware in official letters that highlight their leadership and the other skills they demonstrate.

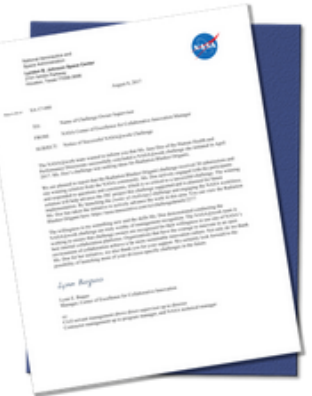

Come explore some of our latest Challenges. Or maybe you want to become a Challenge Owner yourself! If this piques your interest, here 5 simple steps to make the most out of Owning your Challenge.

Please don't hesitate to ask if you have any questions. We are happy to have you as part of the NASA@work community.

\section{T5: Platform recognition}

Thanks for being part of the NASA@work community.

The NASA@work ideation platform allows us to draw on the creative minds across the entire Agency to make wonderful things happen! Challenge Owners who identify issues and bring the Challenge process to fruition are crucial since the best solutions can only be as good as the underlying problems they address.

This is why we have decided to shine a light on the Challenge Owners behind our Coolest Challenges. From now on, they will be inducted in the newly created NASA@work Wall of Fame and recognized in the NASA@work Monthly Bulletin and in our tweets.

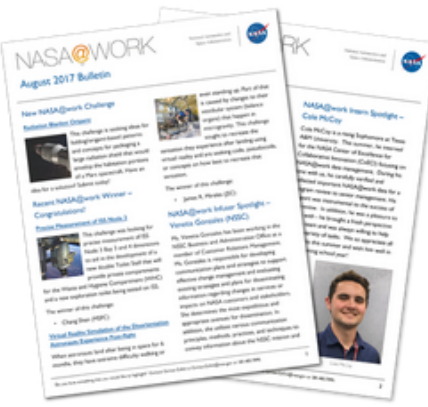

Come explore some of our latest Challenges. Or maybe you want to become a Challenge Owner yourself! If this piques your interest, her

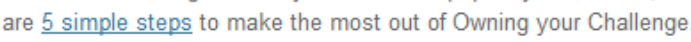

Please don't hesitate to ask if you have any questions. We are happy to have you as part of the NASA@work community. 


\section{T6: Mission \& peer recognition}

Thanks for being part of the NASA@work community.

The NASA@work ideation platform allows us to draw on the creative minds across the entire Agency to make wonderful things happen! Challenge Owners who identify issues and bring the Challenge process to frution are crucial since the best solutions can only be as good as the underlying problems they address.

Contributing to the platform enables all of us to reaffirm NASA's vision to reach for new heights and reveal the unknown so that what we do and learn will benefit all humankind. It allows us to accomplish our mission to drive advances in science, technology, aeronautics, and space exploration to enhance knowledge, education, innovation, economic vitality, and stewardship of Earth.

This is why we have decided to recognize the Challenge Owners behind our Coolest Challenges. From now on, they will receive our NASA@work pin together with a personal letter of appreciation from the NASA@work team.

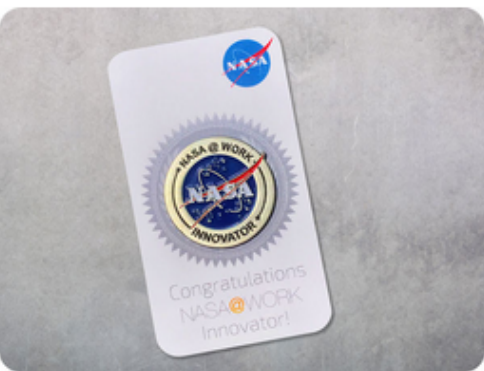

Come explore some of our latest Challenges. Or maybe you want to become a Challenge Owner yourself. If this piques your interest, here are 5 simple steps to make the most out of Owning your Challenge.

Please don't hesitate to ask if you have any questions. We are happy to have you as part of the NASA@work community.

\section{T7: Mission \& managerial recognition}

Thanks for being part of the NASA@work community.

The NASA@work ideation platform allows us to draw on the creative minds across the entire Agency to make wonderful things happen! Challenge Owners who identify issues and bring the Challenge process to fruition are crucial since the best solutions can only be as good as the underlying problems they address.

Contributing to the platform enables all of us to reaffirm NASA's vision to reach for new heights and reveal the unknown so that what we do and learn will benefit all humankind. It allows us to accomplish our mission to drive advances in science, technology aeronautics, and space exploration to enhance knowledge,

education, innovation, economic vitality, and stewardship of Earth.

This is why we have decided to recognize the Challenge Owners behind our Coolest Challenges. From now on, we will make their managers aware in official letters that highlight their leadership and the other skills they demonstrate.

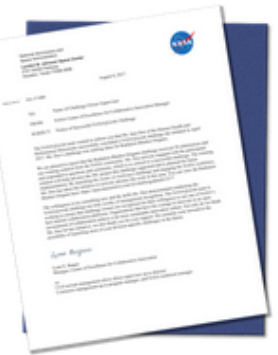

Come explore some of our latest Challenges. Or maybe you want to ecome a Challenge Owner yourself: If this piques your interest,

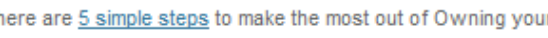
Challenge.

Please don't hesitate to ask if you have any questions. We are happy to have you as part of the NASA@work community.
T8: Mission \& platform recognition

Thanks for being part of the NASA@work community.

The NASA@work ideation platform allows us to draw on the creative minds across the entire Agency to make wonderful things happen! Challenge Owners who identify issues and bring the

Challenge process to fruition are crucial since the best solutions can only be as good as the underlying problems they address.

Contributing to the platform enables all of us to reaffirm NASA's vision to reach for new heights and reveal the unknown so that what we do and learn will benefit all humankind. It allows us to accomplish our mission to drive advances in science, technology aeronautics, and space exploration to enhance knowledge, education, innovation, economic vitality, and stewardship of Earth.

This is why we have decided to shine a light on the Challenge Owners behind our Coolest Challenges. From now on, they will be inducted in the newly created NASA@work Wall of Fame and recognized in the NASA@work Monthly Bulletin and in our tweets.

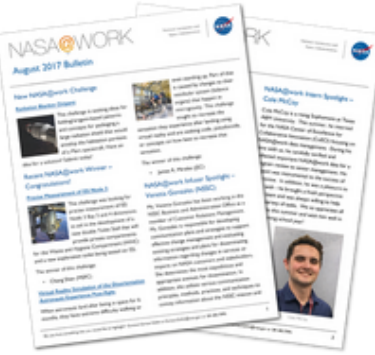

Come explore some of our latest Challenges. Or maybe you want to the Challenge.

Please don't hesitate to ask if you have any questions. We are happy to have you as part of the NASA@work community. 